\title{
Impact of Different Surface Treatments on Flexural Strength and Surface Roughness of Zirconia Implant Material: An In Vitro study
}

\author{
Karthik Kannaiyan ${ }^{1}$, Mohammad Jalaluddin ${ }^{2}$, Aradhana Rathod ${ }^{3}$, KV Rahul Ramesh ${ }^{4}$, Shreya Gupta ${ }^{5}$, Nisarga Kansar ${ }^{6}$
}

\begin{abstract}
Aim: The present study aimed to assess the effect of various surface treatment options on surface roughness and flexural strength of the zirconia implant material.

Materials and methods: This study included a total of 45 prefabricated samples of sintered zirconia disks. Grit papers of silicon carbide (240-1200 $\mu \mathrm{m}$ ) were used to polish the sample surfaces and were then washed with water to clear any particles generated while polishing. These samples were segregated into three groups (15 samples in each group). Group I: control, group II: UV light-treated zirconia disks, group III: sandblasted and acid-etched (SLA)-treated zirconia disks. The surface characteristics of test samples post-surface treatment were evaluated with a scanning electron microscope (SEM). Post-surface treatment of all the three groups, surface roughness was analyzed with a digital optical profilometer. Flexural strength of zirconia samples was assessed using piston on a Universal load testing machine with the three-point bending test.

Results: The highest surface roughness was recorded in SLA-treated zirconia group $(0.524 \pm 0.028)$ next by UV light-treated group $(0.510 \pm$ $0.132)$ and control group $(0.466 \pm 0.016)$. However, there was no statistically significant result seen between the groups. The highest flexural strength was found in the control group $(596.21 \pm 1.246)$ next by UV light-treated $(488.45 \pm 2.108)$ and SLA-treated zirconia group $(424.67 \pm$ 1.022). A statistically significant result was recorded between groups I and II, groups I and III ( $p<0.001)$.

Conclusion: The highest surface roughness was recorded in the SLA-treated zirconia group followed by the UV light-treated group and the control group. There was a statistically significant difference noted for flexural strength between the control group with the SLA group and the UV light-treated group.

Clinical significance: The ongoing research in dentistry aims for enhancements in the bioactivity of zirconia implants so as to achieve improved healing and lowered morbidity. Now a days, zirconia is gradually emerging as an important material that might substitute the gold standard of the dental implant.

Keywords: Dental implant, Flexural strength, Surface roughness, Zirconia.

World Journal of Dentistry (2021): 10.5005/jp-journals-10015-1797
\end{abstract}

\section{INTRODUCTION}

The well-established treatment option for oral reintegration post tooth loss is restoration with dental implants. Pure titanium has been the chosen material since decades and continues to be the material of choice for intraosseous dental implants. But, these titanium implants have esthetic concerns, particularly in the anterior part of maxilla. The neck of the implant becomes visible due to gingival recession. Moreover, titanium results in immunologic reactions with initial local infection leading to probable risk for loss of implants. ${ }^{1}$

Zirconia is the most extensively used dental material by dentists and patients these days because of their superior mechanical properties, such as high fracture toughness (7-10 $\mathrm{MPa} \mathrm{m}^{1 / 2}$ ), flexural strength (700-1200 MPa), high natural appearance, and biocompatibility. Therefore, the zirconia ceramic material is widely used clinically particularly as frameworks for fixed restorations and implant abutments. $^{2}$

Zirconia has been developed as an alternate for the titanium implant over the last few years because of its ability to osseointegrate and due to its other valuable properties such as its color that mimics the color and translucency of natural teeth. ${ }^{3}$ Zirconia can easily be seen on the radiographs as it is a radiopaque material alike titanium. Zirconia is associated with less colonization by bacteria compared to
${ }^{1}$ Department of Prosthodontics, Faculty of Dentistry, Melaka Manipal Medical College, Melaka, Malaysia

${ }^{2}$ Department of Periodontics and Oral Implantology, Kalinga Institute of Dental Sciences, KIIT Deemed to be University, Bhubaneswar, Odisha, India

${ }^{3}$ Health and Family Welfare Department, Kalaburagi, Karnataka, India

${ }^{4}$ Department of Prosthodontics, Century International Institute of Dental Sciences, Kasargod, Kerala, India

${ }^{5}$ Department of Prosthodontics, Triveni Dental College, Bilaspur, Chhattisgarh, India

${ }^{6}$ Department of Pedodontics and Preventive Dentistry, Subbaiah Institute of Dental Sciences, Shivamogga, India

Corresponding Author: Karthik Kannaiyan, Department of Prosthodontics, Faculty of Dentistry, Melaka Manipal Medical College, Melaka, Malaysia, Phone: +91 8951739404, e-mail: karthik.844@gmail. com

How to cite this article: Kannaiyan $\mathrm{K}$, Jalaluddin $\mathrm{M}$, Rathod $\mathrm{A}$, et al. Impact of Different Surface Treatments on Flexural Strength and Surface Roughness of Zirconia Implant Material: An In Vitro study. World J Dent 2021;12(1):38-41.

Source of support: Nil

Conflict of interest: None

(c) Jaypee Brothers Medical Publishers. 2021 Open Access This article is distributed under the terms of the Creative Commons Attribution 4.0 International License (https://creativecommons.org/licenses/by-nc/4.0/), which permits unrestricted use, distribution, and non-commercial reproduction in any medium, provided you give appropriate credit to the original author(s) and the source, provide a link to the Creative Commons license, and indicate if changes were made. The Creative Commons Public Domain Dedication waiver (http://creativecommons.org/publicdomain/zero/1.0/) applies to the data made available in this article, unless otherwise stated. 
that with titanium. Zirconia is more biocompatible than titanium as titanium leads to release of corrosion products at the place where implants are positioned. ${ }^{4}$

Surface properties of a biomaterial play a fundamental role in the osseointegration process. Increased surface roughness of dental implants resulted in greater bone apposition and reduced healing time. Sandblasted and acid-etched (SLA) is used to induce surface erosion by applying a strong acid onto the blasted surface. This treatment combines blasting with $\mathrm{Al}_{2} \mathrm{O}_{3}$ with a grain size of $150 \mu \mathrm{m}$ and acid etching sequentially to obtain macroroughness and micropits to increase the surface roughness as well as osseointegration and more recently, ultraviolet radiation has been used to increase the hydrophilic properties of the zirconia implants. ${ }^{5}$ Hence, the present study was done to evaluate the influence of diverse surface treatments on surface roughness and flexural strength of the zirconia implant material.

\section{Materials and Methods}

This in vitro study was conducted in the Department of Prosthodontics and Implantology. This study included a total of 45 prefabricated samples of sintered zirconia disks (Ceramic Industries Pvt. Ltd, India). Grit papers of silicon carbide (240-1200 $\mu \mathrm{m})$ were used to polish the sample surfaces and were then washed with water to clear any particles generated while polishing. Ultrasonic cleaning was done using distilled water for 5 minutes. Fifteen zirconia specimens were used as control. The leftover zirconia samples were exposed to surface treatments.

Forty-five samples $(10 \mathrm{~mm} \times 3 \mathrm{~mm})$ of zirconia disks were segregated into three groups (Fig. 1).

\section{Group I: Control}

Grit papers of silicon carbide were used to polish the samples surfaces and were not exposed to any surface treatments.

\section{Group II: UV Light-treated Zirconia Disks}

In this group, 15 samples were treated for 15 minutes with UV light using a UV activation device. The UV light was delivered through a single source $(\lambda=360 \mathrm{~nm}$ and $\lambda=250 \mathrm{~nm}$ ) as a spectral mixture.

\section{Group III SLA-treated Zirconia Disks}

Diamond paste of $3 \mu \mathrm{m}$ was used to polish smooth surfaces of zirconia disks, while $\mathrm{Al}_{2} \mathrm{O}_{3}$ with a grain size of $150 \mu \mathrm{m}$ and pressure 6 bar was used to sandblast the roughened surfaces, followed by
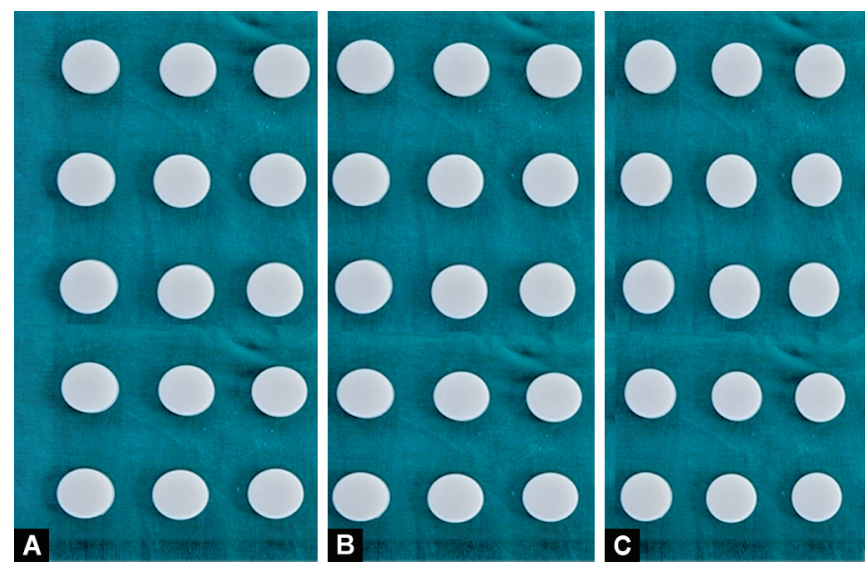

Figs 1 A to C: Present study zirconia disks groups: (A) Control; (B) UV light-treated; (C) SLA-treated acid etching for 10 seconds with 38-40\% hydrofluoric acid (HF). Double distilled water was used to clean all samples, followed by use of double distilled water for ultrasonic cleaning for 5 minutes, followed by air-drying (Fig. 2).

\section{Evaluation of Samples under Scanning Electron Microscopy}

Post-surface treatment, the surface characteristics of test samples were evaluated using a scanning electron microscope (SEM). All the samples were mounted with the mounting plate and $90 \%$ ethanol was used to spray the samples. Later, the chamber was filled with vacuum. A camera is used within the SEM machine lens to focus precisely at the center of the sample. A $3000 \times$ magnification was used to record all the sample images (Figs 3 and 4).

A digital optical profilometer 210 speed of stylus; $0.5 \mathrm{~mm} /$ second that was connected to a computer software was used to assess the surface roughness after the surface treatment of all the three groups.

A piston on three-point bending test on a universal load testing machine was used to determine the flexural strength of zirconia samples. A special custom-made jig attached to the Universal testing machine was used to apply load to the center of the samples. The samples were loaded in a universal testing machine at $5 \mathrm{~mm} /$ minute cross-head speed until the samples were fractured.

\section{Statistical Analysis}

A SPSS software version 20.0 was used to analyze the collected data. As data were normally distributed, the flexural strength between the groups was measured using the one-way analysis of variance (ANOVA). A $p$ value of less than 0.05 was considered as statistically significant.

\section{Results}

The mean of surface roughness and flexural strength of different groups post-surface treatment are as shown in Table 1. The highest surface roughness was recorded in the SLA-treated zirconia group $(0.524 \pm 0.028)$ followed by the UV light-treated group $(0.510 \pm$ $0.132)$ and the control group $(0.466 \pm 0.016)$. The highest flexural strength was noted in the control group $(596.21 \pm 1.246)$ followed by the UV light-treated group $(488.45 \pm 2.108)$ and SLA-treated zirconia group ( $424.67 \pm 1.022)$.

The comparison of surface roughness of different groups post-surface treatment is as shown in Table 2. A highest surface roughness was recorded in the SLA-treated zirconia group $(0.524$

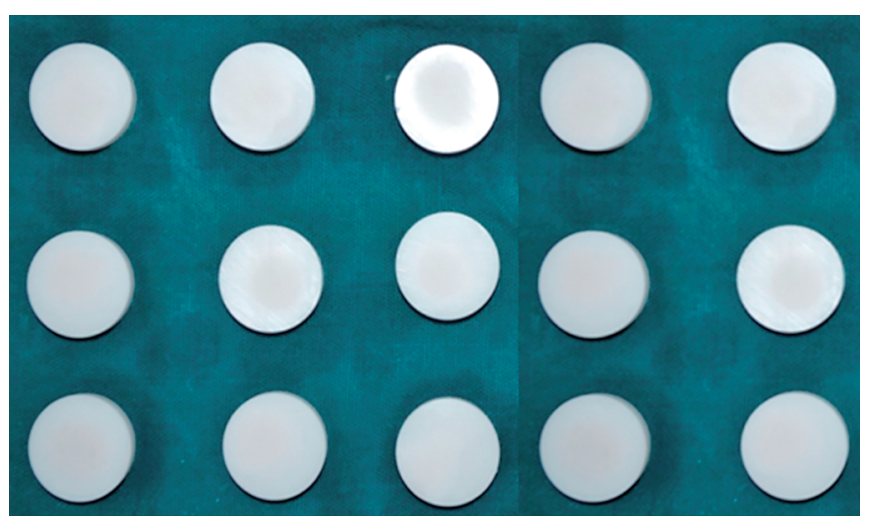

Fig. 2: Zirconia disks after SLA 
\pm 0.028 ); however, no statistically significant results were found between the groups.

When flexural strength of different groups post-surface treatment was compared, a statistically significant result was found between groups I and II, groups I and III $(p<0.001)$ and this is as shown in Table 3.

\section{Discussion}

"Dental implants have led to the enhancement of many patients" quality of life. Currently, use of implants as a treatment option is the most prevalent prosthetic solution, specifically in instances of anterior teeth replacement where esthetics is a concern. The increased expectations and demand from patients for esthetic dental treatment is growing progressively, which has increased the interest of clinicians in the osseointegration and success of the implant. The surface qualities of dental implants are considered to assume a significant part in their clinical achievement. One of the more significant surface attributes of implants is the surface topography or roughness. The level of roughness is resolved either by the machining process during the preparation of the implant or by the resulting alteration of the surface. ${ }^{6}$ So, the present study was considered UV light and SLA was the surface treatment methods.

The chief reasons for the beneficial clinical use of zirconia implants are their good dimensional stability and chemical composition, biocompatibility, adequate hardness, tooth-mimic color, reduced thermal conductivity, ease of use with machines,

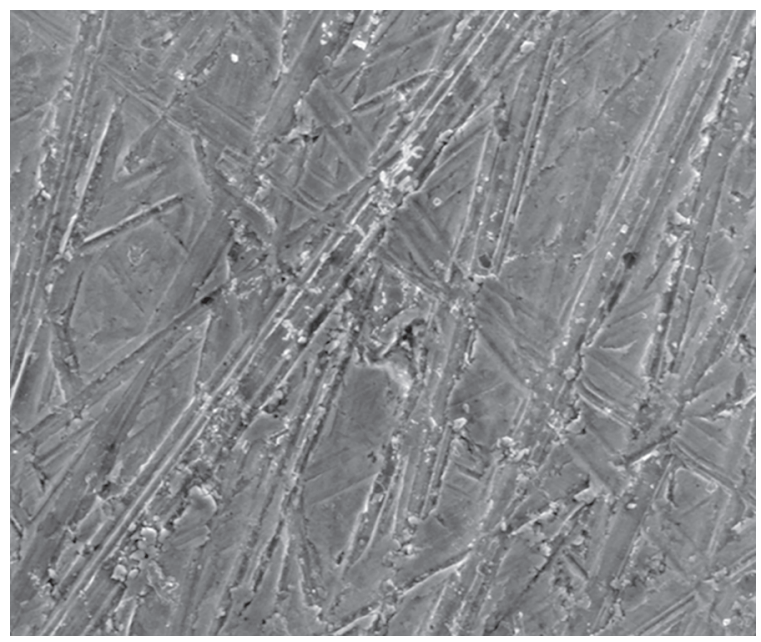

Fig. 3: SEM image of the polished zirconia disk increased flexural strength and Weibull modulus, osseointegration comparable to titanium implants, decreased plaque accumulation, and reduced corrosion risk. ${ }^{7,8}$ In this study, zirconia was taken as an investigational material. This is in accordance with the

Table 1: Mean and standard deviation of different group's surface roughness and flexural strength after the surface treatment

\begin{tabular}{lll}
\hline Groups & $\begin{array}{l}\text { Surface roughness } \\
\text { (mean } \pm \text { SD) }\end{array}$ & $\begin{array}{l}\text { Flexural strength } \\
\text { (mean } \pm \text { SD) }\end{array}$ \\
\hline $\begin{array}{l}\text { Group I: Control } \\
\begin{array}{l}\text { Group II: UV light- } \\
\text { treated zirconia disks }\end{array}\end{array}$ & $0.466 \pm 0.016$ & $596.21 \pm 1.246$ \\
$\begin{array}{l}\text { Group III: Sandblasted } \\
\text { and acid-etched treated } \\
\text { zirconia disks }\end{array}$ & $0.524 \pm 0.028$ & $488.45 \pm 2.108$ \\
\hline
\end{tabular}

Table 2: Comparison of different group's surface roughness after the surface treatment

\begin{tabular}{lllll}
\hline Groups & Mean \pm SS & Fvalue & pvalue & Significance \\
\hline Group I: Control & $0.466 \pm 0.016$ & 20.183 & 0.18 & NS \\
Group II: UV light- & $0.510 \pm 0.132$ & & & \\
treated zirconia & & & & \\
disks & & & & \\
Group III: Sandblast- & $0.524 \pm 0.028$ & & & \\
ed and acid-etched & & & & \\
treated zirconia & & & & \\
disks & & & \\
\hline
\end{tabular}

$p>0.05 ; \mathrm{NS}$, not significant

Table 3: Comparison of different group's flexural strength after the surface treatment

\begin{tabular}{lllll}
\hline Groups & Mean \pm SD & Fvalue & p value & Significance \\
\hline Group I: Control & $596.21 \pm 1.246$ & 29.263 & 0.001 & $\mathrm{HS}$ \\
$\begin{array}{l}\text { Group II: UV light- } \\
\text { treated zirconia }\end{array}$ & $488.45 \pm 2.108$ & & & \\
disks & & & & \\
Group III: & $424.67 \pm 1.022$ & & & \\
Sandblasted & & & & \\
and acid-etched & & & & \\
treated zirconia & & & \\
disks & & & & \\
\hline
\end{tabular}

Post hoc Tukey test—group I vs. group II, group I vs. group III- $p<0.001$ $p<0.05, \mathrm{HS}$, highly significant
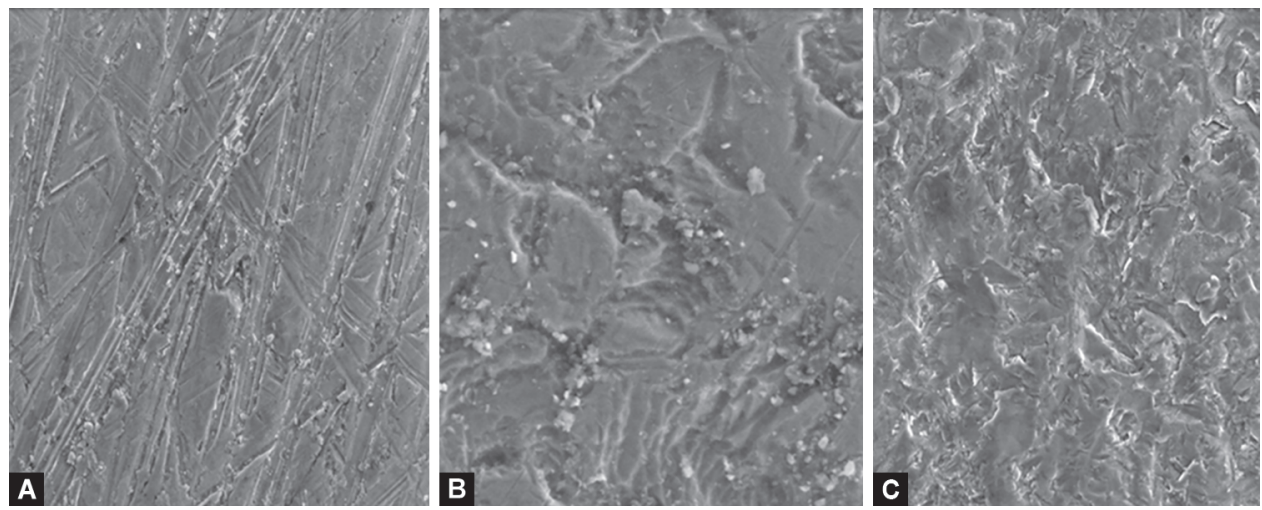

Figs 4A to C: SEM images after surface treatment: (A) Control; (B) UV light-treated; (C) SLA-treated 
study conducted by Gahlert et al..$^{9}$ who also used the roughness of the zirconia implant material on microscale to assess the osseointegration.

In the present study, the surface roughness was found to be more in the SLA-treated zirconia group followed by the UV lighttreated group and the control group. These results are similar to those obtained by Bachle et al. ${ }^{10}$ and Gahlert et al., ${ }^{11}$ who demonstrated an increase in surface roughness by acid etching and air-borne particles. With the change in surface topography, the physics and surface chemistry may change as well. In 2009, Hisbergues et al. ${ }^{12}$ demonstrated that acid etching of zirconia does not provide surface roughness. This result is contradictory to the present study results. In 2009, Andreiotelli et al. ${ }^{13}$ reported that reduced thermal degradation may weaken zirconia's surface stability and thereby probably resulting in sand blasted implant's promotion failure.

A study by Att et al. ${ }^{14}$ stated that the zirconia surface may transform from the hydrophobic to hydrophilic state after UV light treatment. This could be the cause of reduced surface roughness in UV light-treated group when compared to the SLA zirconia group. It was demonstrated by Han et al. ${ }^{15}$ that hydrophilicity improves with UV radiation, thus advocating absence of surface roughness with UV radiation as there is no difference in surface texture.

In this study, flexural strength was highest in the control group followed by the UV light-treated group and lowest with the SLAtreated zirconia group. Although it was statistically significant, this could be ascribed to the manufacturing procedure and the physical and chemical composition shows significant differences. ${ }^{16}$ Surface hardness is considered as density indicator and it can be assumed that the denser material would have added resistance to surface determination and wear. ${ }^{17}$

The limitation of the present study could be the microflora around implants is similar to that of natural teeth; microbial pathogens associated with periodontitis may contribute to implant failure. Hence, further research should be conducted to evaluate an adhesion of oral bacteria. And effect of UV light on in vivo on osteoconductive potential of zirconia should be the target of exploration and the impact of these changes and suitability of zirconia for its use as the dental implant material.

\section{Conclusion}

The highest surface roughness was recorded in the SLA-treated zirconia group followed by the UV light-treated group and the control group. There was a statistically significant difference noted for flexural strength between the control group with the SLA group and the UV light-treated group.

\section{References}

1. Jacobi-Gresser E, Huesker K, Schutt S. Genetic and immunological markers predict titanium implant failure: a retrospective study.
Int J Oral Maxillofac Surg 2013;42(4):537-543. DOI: 10.1016/j. ijom.2012.07.018.

2. Kirmali O, Kustarci A, Kapdan A. Surface roughness and morphologic changes of zirconia: effect of different surface treatment. Niger J Clin Pract 2015;18:124-129.

3. Jackson MC. Restoration of posterior implants using a new ceramic material. J Dent Technol 1999;16:19-22.

4. Tschernitschek H, Borchers L, Geurtsen W. Nonalloyed titanium as a bioinert metal- a review. Quintessence Int 2005;36:523-530.

5. Zechner W, Tangl S, Fürst G, et al. Osseous healing characteristics of three different implant types. Clin Oral Implants Res 2003;14(2):150157. DOI: 10.1034/j.1600-0501.2003.140203.x.

6. Zembic A, Sailer I, Jung RE, et al. Randomized controlled clinical trial of customized zirconia and titanium implant abutments for single-tooth implants in canine and posterior regions: 3-year results. Clin Oral Implants Res 2009;20(8):802-808. DOI: 10.1111/j.16000501.2009.01717.x.

7. Sennerby L, Dasmah A, Larsson B, et al. Bone tissue responses to surface-modified zirconia implants: a histomorphometric and removal torque study in the rabbit. Clin Implant Dent Relat Res 2005;7(s1):13-20. DOI: 10.1111/j.1708-8208.2005.tb00070.x.

8. Gahlert $M$, Burtscher $D$, Grunert I, et al. Failure analysis of fractured dental zirconia implants. Clin Oral Implants 2012;23(3):287-293. DOI: 10.1111/j.1600-0501.2011.02206.x.

9. Gahlert M, Rohling S, Wieland M, et al. A comparison study of the osseointegration of zirconia and titanium dental implants. A biomechanical evaluation in the maxilla of pigs. Clin Implant Dent Relat Res 2010;12(4):297-305. DOI: 10.1111/j.1708-8208.2009.00168.x.

10. Bachle M, Butz F, Hubner U, et al. Behavior of CAL72 osteoblastlike cells cultured on zirconia ceramics with different surface topographies. Clin Oral Implants Res 2007;18(1):53-59. DOI: 10.1111/j.1600-0501.2006.01292.x.

11. Gahlert M, Gudehus T, Eichhorn S, et al. Biomechanical and histomorphometric comparison between zirconia implants with varying surface textures and titanium implant in the maxilla of miniature pigs. Clin Oral Implants Res 2007;18(5):662-668. DOI: 10.1111/j.1600-0501.2007.01401.x.

12. Hisbergues $M$, Vendeville $S$, Vendeville P. Zirconia: established facts and perspectives for a biomaterial in dental implantology. J Biomed Mater Res B Appl Biomater 2009;88(2):519-529. DOI: 10.1002/ jbm.b.31147.

13. Andreiotelli M, Wenz HJ, Kohal RJ. Are ceramic implants a viable alternative to titanium implants? a systematic literature review. Clin Oral Implants Res 2009;20:32-47. DOI: 10.1111/j.16000501.2009.01785.x.

14. Att W, Hori N, Takeuchi M, et al. Time-dependent degradation of titanium osteoconductivity: an implication of biological aging of implant materials. Biomaterials 2009;30(29):5352-5363. DOI: 10.1016/j.biomaterials.2009.06.040.

15. Han Y, Yan Y, Lu C. Ultraviolet-enhanced bioactivity of ZrO. Thin Solid Films 2009;517(5):1577-1581. DOI: 10.1016/j.tsf.2008.09.064.

16. Zinelis $S$, Thomas A, Syres $K$, et al. Surface characterization of zirconia dental implants. Dent Mater 2010;26(4):295-305. DOI: 10.1016/j. dental.2009.11.079.

17. Meshramkar R, Shetty P, Anehosur G, et al. Effect of different surface treatment of zirconia on surface roughness, microhardness and flexural strength. Curr Adv in Dental Sci 2020;01(01):6-11. 